\title{
The risk assessment, a decision-making tool for the management of contaminated sites
}

\author{
Ioan Bica $^{1, *}$ and Anamaria Petruta $^{2}$ \\ ${ }^{1}$ UTCB, Hydraulic and Environmental Department, 020378, Bucharest, Romania \\ ${ }^{2}$ UTCB, Doctoral School, 020378, Bucharest, Romania
}

\begin{abstract}
The paper presents a methodology to assess the solutions for the management of contaminated sites. For defining these solutions there were developed two main activities. First one consists in a detailed site investigation to define its geological, hydrogeological characteristics and surely the contamination level. The second activity is dedicated to the assessment of risk generated by the soil, subsoil, air, and groundwater contamination, by using a professional software. The methodology was applied to a real case study. The results showed that for non-carcinogenic compounds the risk is above the thresholds establish by legislation. The conclusion is that measures to mitigate this risk must be taken, based on a feasibility study that will be realised in the next stage of the research.
\end{abstract}

\section{Introduction}

The management of contaminated zones is a tool that prevents and reduces the negative effects generated by these areas to the environment and surely to human health.

The management program must provide data on the following aspects: the history of the area; its characteristics, including contaminants; impact on internal and external receptors (population and environment); land use restrictions; control of the management of the contaminated area in the context of its current or future use; deficiencies in the current state of information and the need for additional investigations to facilitate decision - making; risk reduction or management requirements for future uses of the area; requirements for future monitoring; future regulatory or reporting requirements.

Among the analysis criteria used to establish the management solution of a contaminated area must be included two general principles deriving from resource management [1]: (i) minimizing future maintenance needs, respectively regulatory requirements to ensure the safe use of the area; (ii) reducing to a reasonable level the constraints of the use of the area.

From a managerial point of view, the measures that can be applied for the management of the contaminated underground environment are limited, so that the decisions in their design seem to be easy from this point of view $[2,3]$ :

- measures to limit (contain) the increase of the polluted area; this means that the area remains polluted, but measures are being taken to protect down-stream receptors;

* Corresponding author: ioan.bica@,utcb.ro 
- measures for restoration (decontamination) of the polluted underground zone; active remediation solutions, through technologies appropriate to the contamination.

- natural attenuation (self-remediation) not taking any remediation measures, relying on the self-decontamination capacity of the underground environment.

The implementation of one of these measures depends on several factors, among which the most important are the risks associated with pollution, the potential uses of the area as a whole and, finally, the self-cleaning capacity of the underground environment.

\section{Risk assessment of a contaminated area}

A useful tool for establishing management options is to assess the environment risk generated by the contaminated area. The risk is defined as the probability of arising of a negative effect combined with the magnitude of its effects. Risk management consists in the implementation of a set of measures, procedures, decisions for its mitigation.

For contaminated areas, the risk assessment defines the procedure by which the hazards generated by contamination to the health of the population or to the ecosystem are estimated qualitatively or quantitatively.

Consequently, the risk targets (receptors) are:

- individuals living in the studied area (children and the elderly, individuals with various allergies and diseases are the most sensitive to various contaminations). Those outside the actual risk area may be affected, due to the transport of pollutants by air, groundwater or surface water and agricultural products.

- ecological systems located in the affected area. The extinction of a species can cause disorder of the entire food chain.

- economic sector. An accident at an industrial plant can destroy others in the vicinity.

\subsection{Ecological risk assessment}

To assess the ecological risk, basic information on the area subject to analysis is required, namely population density and its distribution; main transport routes; topography of the area; hydrographic network; climate and meteorological data; current and future use of the area; the location of the industrial installations, etc.

At the beginning, the risk assessment process consisted in a probabilistic analysis. There are several options on this subject, but in essence the process is to find out what can be disturbed, what is the probability of this event and how dangerous are the consequences. Once this process is completed, the information is combined into an estimation, according to the following relationship:

$$
\mathrm{R}=\mathrm{P} \times \mathrm{G}
$$

where:

$\mathrm{R}$, is the risk of an unforeseen event;

$\mathrm{P}$, probability of occurrence;

$\mathrm{G}$, the severity (magnitude) of the danger.

The objectives of the risk assessment follow their control, by identifying the polluting agents or the most important dangers; resources and receptors exposed to risk; the mechanisms by which the risk is generated; the nature of the important risks that occur on the site; the general measures needed to reduce the magnitude of the risk to an acceptable level. 


\subsection{The concept source-pathway-receptor}

The risk assessments compare the expected concentrations of pollutants in the environment with the environment legislation permitted toxic thresholds.

The qualitative risk assessment considers the following factors (Figure 1):

- Source / Hazard - refers to specific pollutants that are identified or suspected to exist at a site, their level of toxicity (concentration) and their toxic effects.

- Pathway of action - are the routes (migration through soil, air, or water) by which toxic substances reach the point where they have harmful effects (ecosystem components), either by direct ingestion, inhalation, or dermal contact.

- Target / Receptor - represents the ecosystem components on which the harmful effects of certain toxic substances on the site act; these may include humans, animals, plants, water resources and buildings, etc.
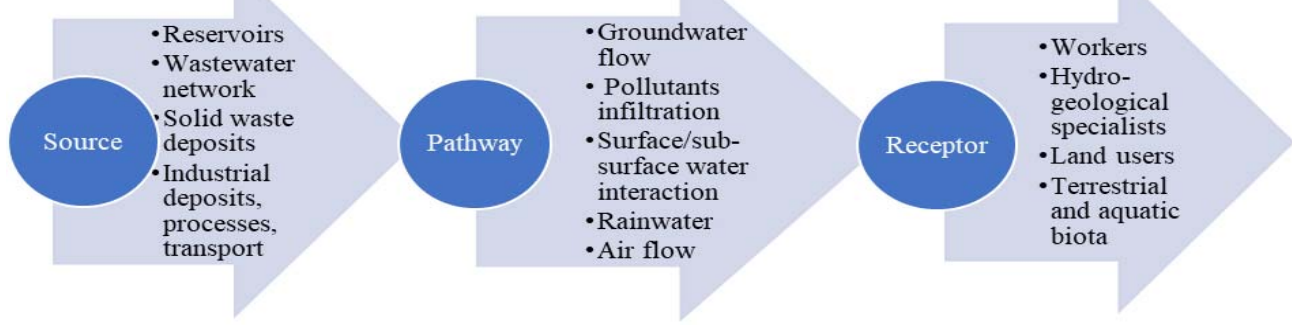

Fig. 1. Risk assessment. Source-pathway-receptor scheme.

The risk can then be calculated by multiplying the probability factor with the severity factor, to obtain a comparative figure. This allows comparisons to be made between different risk scenarios. The higher the result, the higher the priority that will have to be taken in controlling the risk.

The starting elements in the construction of this diagram are the environmental factors air, water, soil (ways of transmitting pollutants), with their subcomponents.

The diagram in the figure then serves for the construction of the detailed source - path receptor diagrams for each environmental factor and for the specific conditions of the contaminated area, respectively of the dangerous substance.

Recently, mathematical codes, based on the concept described above, have been developed to evaluate the transport of pollutants from a contaminated area, using various vectors and transport mechanisms (air, water, soil), determining their concentrations at the level of receptors and assessing their toxic or carcinogenic risk to the population, as it is presented in the next chapter.

\section{RBCA Toolkit for risk assessment}

The RBCA Tool Kit for Chemical Releases is a comprehensive modelling and risk characterization software package. The RBCA combines contaminant transport models and risk assessment tools to calculate baseline risk levels and derive risk-based clean-up standards for a full array of soil, groundwater, surface water, and air exposure pathways. The ease-of-use features and streamlined graphical interface features of this software make it an essential tool for handling RBCA and generic risk assessment for both simple and sophisticated problems [4].

Possible routes of exposure are accidental ingestion, inhalation of vapours and dust, adsorption through skin and polluted media, possible solubilization from soil to 
groundwater, by washing the surface of the soil / subsoil contaminated by rainwater, favours the transfer of pollutants from soil to groundwater (Figure 2).

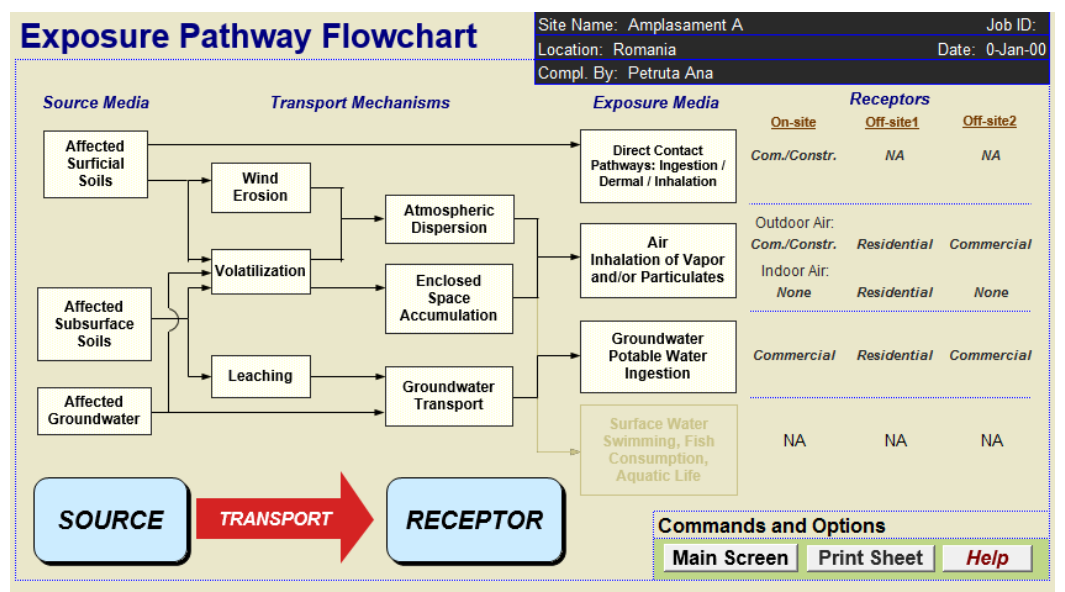

Fig. 2. RBCA Toolkit. Source-pathway-receptor [4].

The general data and procedures used (input, output) of the contaminated site to perform a carcinogenic and non-carcinogenic risk assessment using the RBCA Toolkit software are presented in Table 1.

Table 1. Data base for risk assessment.

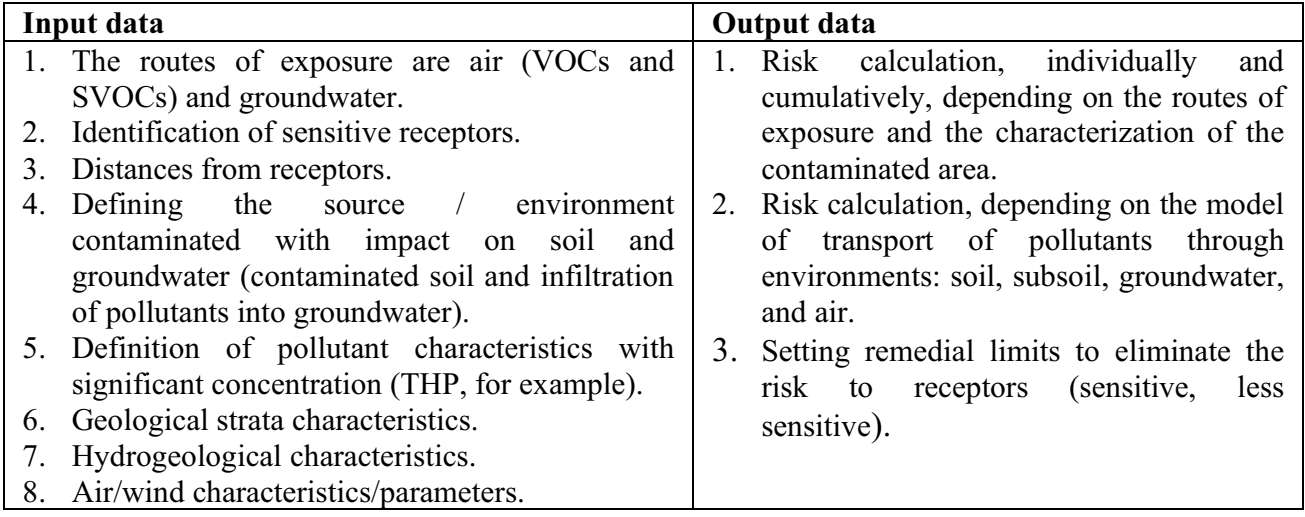

\section{Risk assessment. Case study}

\subsection{Site description}

The case study is carried out for a site where activities for storage and distribution of petroleum products were carried out [5].

From geological point of view (Figure 3), the area is composed at the surface by a filling layer with a thickness of $0.50 \mathrm{~m}$ below which a semi-cohesive formation develops, mainly composed of clayey sandy powders in which there are lenses of clayey sands. This formation has an important thickness of about $10 \mathrm{~m}$ and forms the groundwater aquifer of the studied area. Under this layer develops the formation of the bedrock, impermeable, consisting of marly clays. 
The groundwater level in the terrace area is about $4.50 \mathrm{~m}$ deep, and in the meadow area it is at depths of $1.60 \mathrm{~m}$. During periods of heavy rainfall, the presence of springs is noticeable at the base of the terrace slope. The measurements performed in drillings allowed the determination of the general flow direction of the groundwater aquifer from west to east, as well as the hydraulic gradient of the groundwater aquifer (with values between $0.2 \%$ - $0.21 \%$ ).

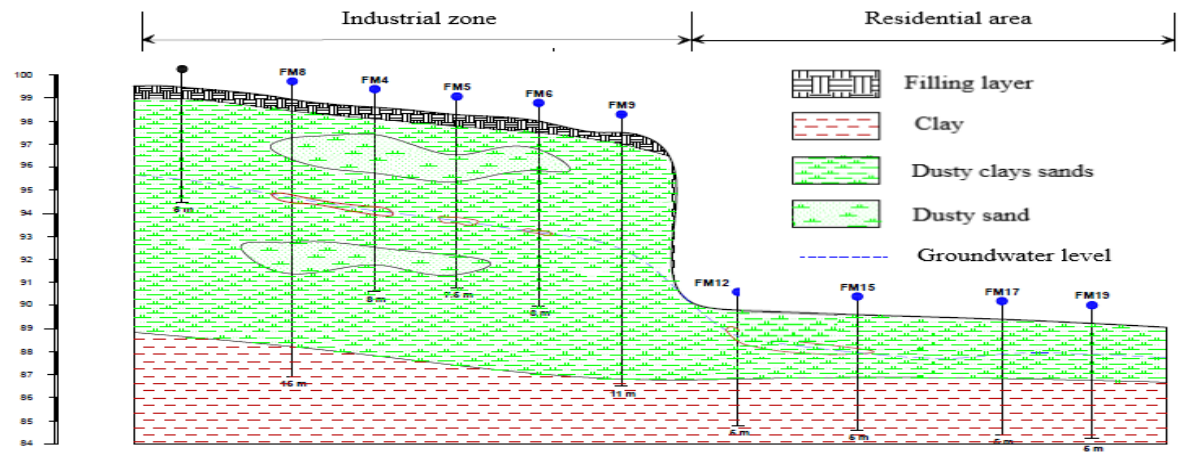

Fig. 3. Lithological profile through the study aria. ( $F=$ Investigation wells; FM = monitoring wells).

Investigations and analytical measurements revealed the contamination of the underground environment (geological strata) with petroleum products, inside the platform (Figure 4), at different depths below the land surface [5].

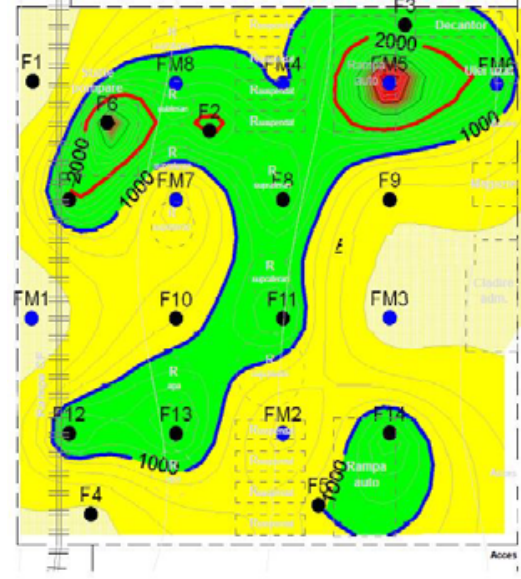

a.

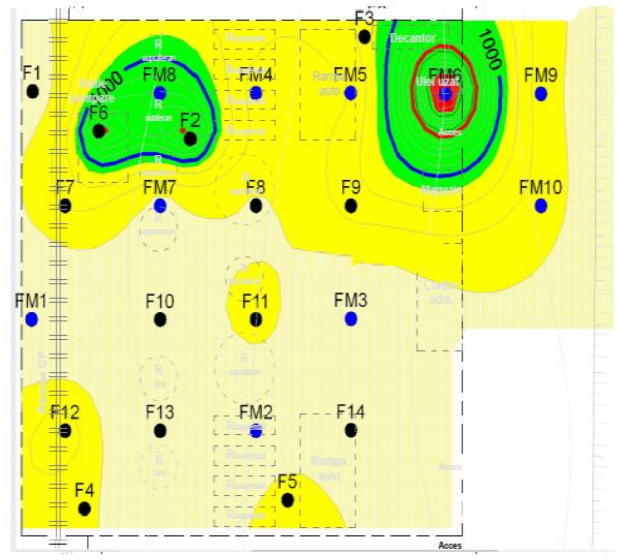

b.

Fig. 4. TPH contamination of geological strata. a. - 1.0m depth; b. $-3.0 \mathrm{~m}$ depth. (legend: $\mathrm{F}=$ investigation well; FM = monitoring well).

The map in Fig 4.a shows that THP contamination of the soil is above the intervention threshold $(2000 \mathrm{mg} / \mathrm{kg})$ for less sensitive lands use, namely around the former constructions: pumping station (F6) and car platform (FM5) from the northern part of the site. THP contamination of the soil is above the alert threshold $(1000 \mathrm{mg} / \mathrm{kg})$ for less sensitive lands use, namely around the former facilities: pumping station (F6), railway platform (F7), the tanks and car platform, both in the southern area (F12, F13, F14), the central (F11) and northern area (F2, FM8, F8, FM4, FM5) of the site, the decanter (F3) and waste oil storage area (FM6). 
The map in Fig 4.b shows that THP contamination of soil (for $3.0 \mathrm{~m}$ depth) is above the intervention threshold $(2000 \mathrm{mg} / \mathrm{kg}$ ) for less sensitive use of the land, namely in the waste oil storage area (FM6). THP contamination of the soil is above the alert threshold (1000 mg $/ \mathrm{kg}$ ) for less sensitive land uses, namely in the pumping station area (F6), the tanks in the northern area of the site (FM8, F2) and in the used oil storage area (FM6).

The data concerning the quality of the soil outside the platform, in the residential area, showed that THP values are found in the normal values. So, no pollution is reported.

The results of the laboratory analysis showed the contamination of groundwater, both in the platform area and downstream of it, in the residential area [5].

The THP concentration in groundwater above the intervention threshold $(0.60 \mathrm{mg} / 1-$ according with Romanian legislation, [5]) were identified in the monitoring boreholes FM8 and FM4 (the reservoirs in the north of the site), FM5 (car platform), FM6 (area of used oil storage) and FM12 in the residential area (Figure 5).

The THP concentration in groundwater above the alert threshold $(0.10 \mathrm{mg} / \mathrm{l})$ were identified in most observation and investigation boreholes except those located in the southern part of the site (FM1, FM2 and FM3), F3 and those in the residential area, namely FM14 and FM19 (Figure 5).

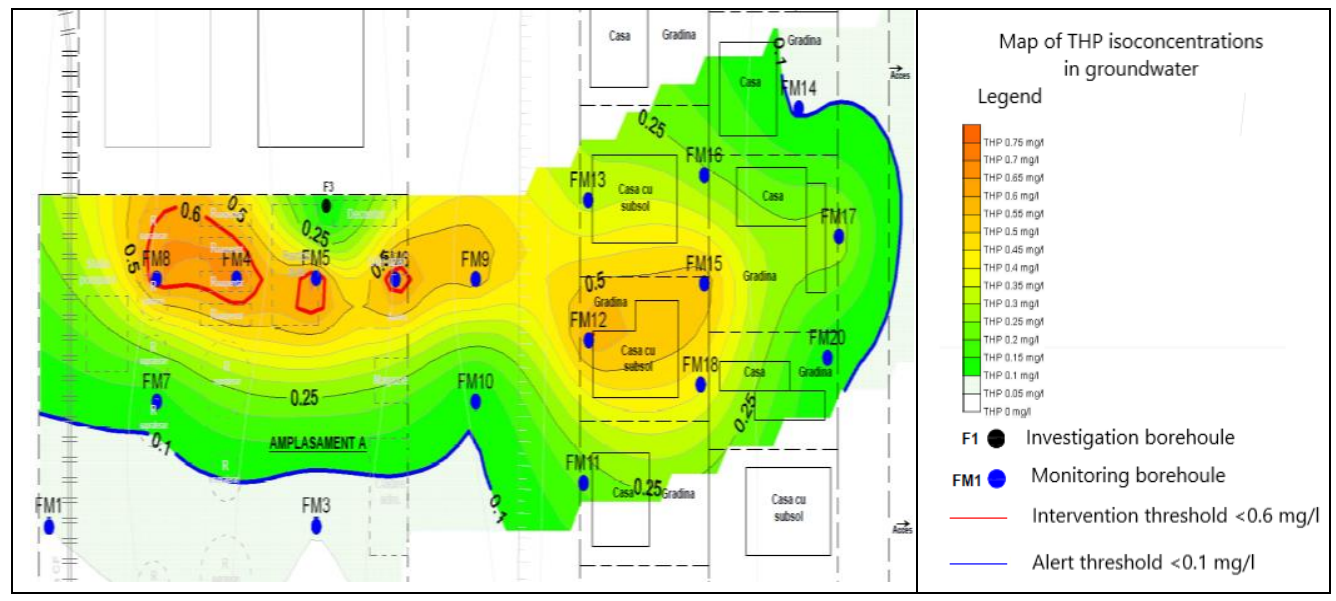

Fig. 5. TPH contamination of groundwater.

\subsection{Results}

Quantitative risk estimation was performed using the RBCA Toolkit for Chemical Releases software version 2.6, applying the ASTM E-2081-00 Standard Guide for Risk-Based Corrective Action (ASTM 2004) and ASTM E-1739-95 Standard Guide for Risk-Based Corrective Action Applied at Petroleum Release Sites. The aim was to define the reference target values considering the characteristic receptors inside (on site) and outside (off site) of the site using progressive and regressive calculation models.

The main routes of exposure of receptors at ground level, considered for this activity (Figure 6), respectively THP, are accidental ingestion, inhalation of vapours and dust, adsorption through skin.

The contaminated groundwater (THP pollutants) as a source of risk, may impact residential receptors. The possible routes of exposure identified are ingestion of groundwater, direct consumption of water, the consumption of food prepared using water from wells located in yards or consumption of irrigated food with contaminated water. 


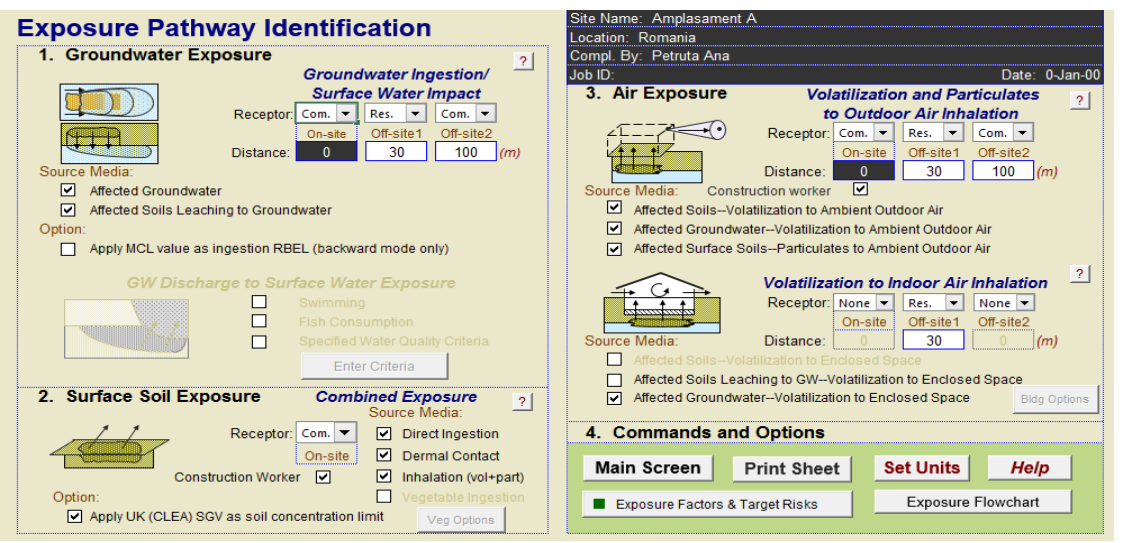

Fig. 6. Pathways of contaminant transfer to receptors (RBCA Toolkit).

All the input data required by RBCA Toolkit were introduced in the soft. In Figure 7 is presented an example of data for groundwater pathway.

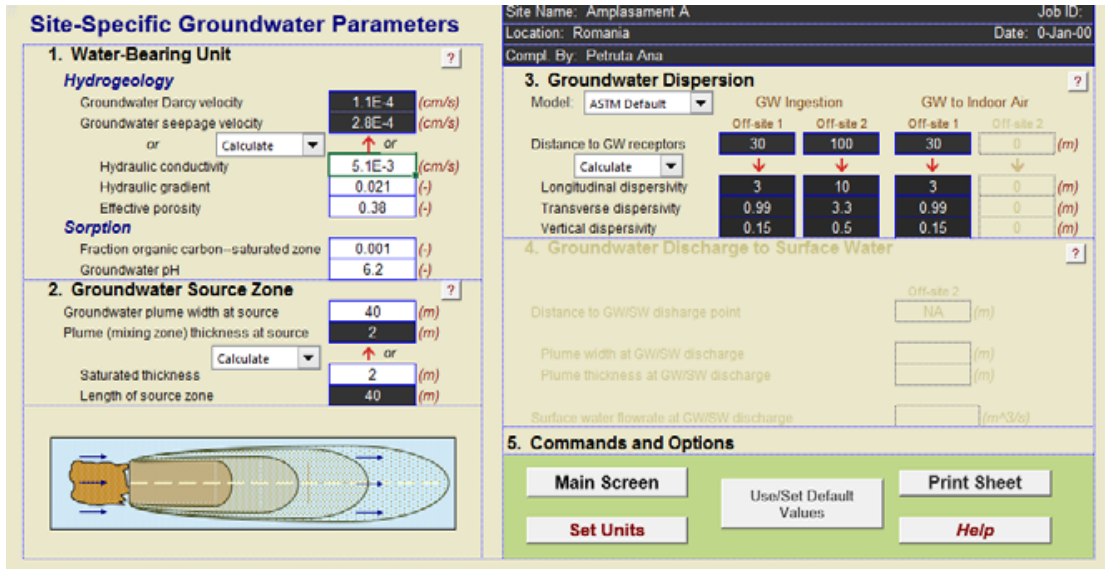

Fig. 7. Site specific parameters for groundwater pathways (RBCA Toolkit).

The modelling results by using the RBCA Toolkit software show that the risk limits are exceeded at the level of receptors for open space air and groundwater exposure routes, by dermal contact with contaminated water, accidental ingestion of contaminated water and emissions of vapor and dust (Table 2).

\section{Conclusions}

Soil contamination on the study site covers a surface of approximately $5890 \mathrm{~m}^{2}$ (around $34 \%$ of the total surface of the site) and an estimated volume of contaminated soil is approximately $29450 \mathrm{~m}^{3}$. Based on the soil analyses performed for THP and benzene, there was noted a significant pollution with petroleum products up to a depth of $5 \mathrm{~m}$ in the reservoirs area, the zone for loading petroleum products and in the waste oil storage zone.

The analyses of the groundwater samples revealed a significant pollution with petroleum products (THP, benzene) inside the platform, and this contamination has migrated outside the site, towards the residential area. 
The risk assessment was performed to identify the contamination/exposure pathways, to model the behaviour of the pollution in the geological environment and the exposure contaminant concentrations, respectively to quantify the individual and / or cumulative risk.

Table 2. Risk assessment results (RBCA Toolkit).

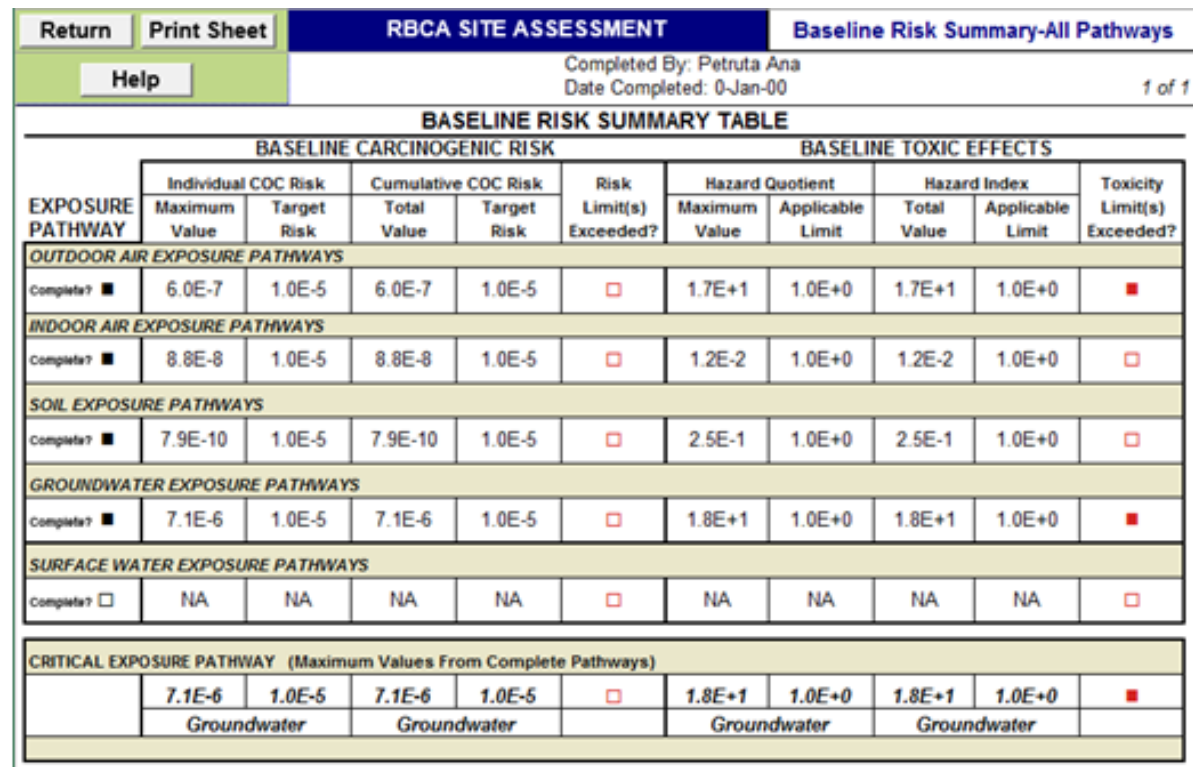

The results of risk assessment show that the carcinogenic risk is below the regulated threshold, and only toxic risk is above the threshold, according to Romanian legislation [6].

Based on the characterization of the site through the specialized software for RBCA risk assessment, there was identified a non-carcinogenic risk at groundwater and air level for the receptors identified on site (workers during remediation works) but also off site (people in the residential area).

To minimize the risk, it is proposed to carry out feasibility studies for soil decontamination (in situ methods - bioremediation, phytoremediation, or soil washing) and groundwater depollution by ex-situ methods (pump and treat) or is situ (funnel and gate).

\section{References}

1. Guidelines for the assessment of on-site containment of contaminated soil. Australia and New Zealand Environment and Conservation Council, (1999).

2. A.J., Cherry, Developing rational goals for in situ remedial technologies (Subsurface Restoration Conference, Dallas, USA, 1992)

3. I. Bica, Remediation of contaminated sites. (Printing House, "Orizonturi Universitare Timisoara", Timisoara, 2014)

4. RBCA Tool Kit for Chemical Releases Manual (GSI Environmental Inc. Norfolk St. Suite 1000 Houston, TX 77098, 2012)

5. A.M. Petruta, Solutions to minimise the risks posed by industrial decommissioned landfills. PhD Thesis UTCB, (UTSB, Bukharest, 2021)

6. Ministerial Order no. 756/1997 for the approval of the Regulation on the assessment of environmental pollution. Ministry of Environment, Romania (1997) 